\title{
Planejamento estratégico na Comunicação Organizacional (re)significado pelo olhar do Paradigma da Complexidade
}

\author{
Caroline Delevati Colpo
}

\section{A contextualização do Paradigma da Complexidade}

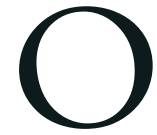

Paradigma da Complexidade considera o "homem complexo" como parte e como o todo, ambas cheias de razão e emoção, um Homo sapines, faber e economicus e também um Homo demens, ludens e consumans ao mesmo tempo. Entende o sujeito como "parte" de tudo o que desenvolve e como "o todo" de todas suas ações, sendo capaz de (re)construir seus espaços e (re)construir a si mesmo (Morin, 2007). Pelo olhar da Complexidade o sujeito é mutante, instável, não fixo e (re)construído constantemente. Através da perspectiva da Complexidade de sujeitos complexos, que utiliza-se neste texto, outro pensamento de Morin (2007), que sugere que não há teoria sem brecha, não há pensamento sem risco, e que na brecha, no risco, na incerteza, na desordem é que se pode gerar novos conhecimentos. Assim procura-se na brecha, na incerteza, no risco do sujeito complexo novas formas de se pensar a comunicação organizacional e o planejamento estratégico para novos conhecimentos.

O Paradigma da Complexidade coloca o sujeito e seu pensamento como peça fundamental da produção de conhecimento. O Paradigma abre os limites do pensamento (e os limites das ciências também) para possibilitar a intervenção do sujeito sobre o conhecimento, uma vez que as ciências ditas "normais" ou "duras" excluem o sujeito do conhecimento. No Paradigma da Complexidade o operador do conhecimento precisa tornar-se seu objeto. Assim, o pesquisador que procura produzir um novo conhecimento pode levar em consideração as premissas do Paradigma, e não fazer do seu uso apenas uma forma de metodologia. Por isto, o Paradigma da 
Complexidade se apresenta como um método para a possibilidade de reconstrução do conhecimento do planejamento estratégico na comunicação organizacional.

O método auxilia a pensar por si mesmo para responder ao desafio da complexidade dos problemas, diferente da metodologia, que são as guias que programam as pesquisas (Morin, 2008a). O método não é o caminho, é a caminhada: ao invés de apenas separar, pode juntar; ao invés de só explicar, necessita compreender. O método não possibilitará uma resposta finalizada, uma conclusão. O método, como Morin (2008a) aponta, se torna uma forma de pensar, na qual, o pesquisador precisa integrar caminhada e caminho, sem excluir nenhuma das possibilidades.

Integrando todas as formas de pensar o Paradigma da Complexidade, busca-se substituir os pensamentos que separam por pensamentos que unem, através de uma substituição da linearidade pela transdisciplinaridade (Morin, 2008a). O pensamento complexo se autoproduz, no sentido de que quanto mais problematiza um objeto de estudo, mais problemas de pesquisa surgem. Sob esta perspectiva este texto introduz o questionamento sobre a aplicabilidade do planejamento estratégico na comunicação organizacional e as possibilidades de (re)significa-los para ampliar a sua capacidade de comunicação entre os sujeitos complexos contemporâneos que compõem as organizações.

Morin (1991) descreve o pensamento complexo como algo que originariamente se tece junto, um pensamento que se desenvolve sem limites disciplinares, buscando distinguir (não separar) e ligar. Afirma que só se pode gerar conhecimento se for possível conhecer as partes que integram o todo, e que só se pode conhecer o todo se forem conhecidas as partes que o compõem. Três princípios, sugeridos por Morin (1991) auxiliam a entender o pensamento complexo aplicado neste trabalho: o princípio dialógico que permite manter a dualidade no seio da unidade, associando, ao mesmo tempo, movimentos complementares e antagônicos; o princípio recursivo que é um processo em que os produtos e os efeitos são ao mesmo tempo causas e produtores daquilo que os produziu, o sujeito é simultaneamente produzido e produtor, rompendo a ideia linear de causa/efeito, de produto/produtor, de estrutura/ superestrutura, uma vez que tudo o que é produzido volta sobre o que produziu num ciclo auto-constitutivo, auto-organizador e autoprodutor; e, por fim, o princípio hologramático, no qual não apenas a parte está no todo, mas o todo está na parte. Estes três princípios, aparentemente paradoxais, subvertem o espírito linear.

Na lógica recursiva, sabe-se muito bem que o que se adquire como conhecimento das partes regressa sobre o todo. O que se aprende sobre as qualidades emergentes do todo que não existe sem organização, regressa sobre as partes. Então pode enriquecer-se o conhecimento das partes pelo todo e do todo pelas partes, num mesmo movimento produtor de conhecimentos. Portanto a ideia hologramática está ligada à ideia recursiva, que por sua vez está ligada à ideia dialógica em parte. (Morin, 1991: 90) 
Sob esta perspectiva, neste trabalho, é desenvolvida a tentativa de uma compreensão do planejamento estratégico na comunicação organizacional (re)significada, para além do midiático e instrumental, com fundamentação em processos comunicacionais estabelecidos entre sujeitos. Esta comunicação, entre os sujeitos e a organização e entre os sujeitos organizacionais, está em processo constante de (re)construção e pode colocar em questionamento os princípios norteadores de um planejamento estratégico de comunicação que visa, na medida da sua funcionalidade, a obtenção de objetivos pré-definidos para o bom desempenho da organização, sem necessariamente, considerar as reconstruções tanto da organização como dos sujeitos.

Ainda segundo Morin (2002), para a construção do conhecimento há necessidade da relação dialógica para a auto-eco-organização. Morin alerta constantemente que é necessário considerar o meio como uma forma de organização complexa, a qual, como um todo, sofre, comporta, produz desordem e ordem em uma relação dialógica. Assim, surge a ideia do anel eco-organizador que começa a indicar que não apenas uma reorganização permanente responde à desorganização também permanente, mas, sobretudo que o processo de reorganização se encontra no próprio processo de desorganização (Morin, 2002). As desordens não fazem retroceder a ordem anterior, mas sim remetem a uma nova ordem. A constante reorganização é produção permanente de outra ordem que ainda não havia sido contemplada. Desta forma, o sistema complexo torna-se implicado, proporcionalmente, pelo aumento de ordem, de desordem, de organização e de reorganização.

A organização proposta por Morin (1991) acontece em uma relação dialógica de eco-organização: não é a estabilidade, mas a aptidão para construir novas estabilidades; não é o retorno ao equilíbrio, mas a aptidão de reorganização, de reorganizar a si mesma de novas maneiras, sob o efeito de novas desorganizações. Isso ocasiona a evolução sob a irrupção perturbadora do novo, e esta aptidão evolutiva é que permite à vida não somente sobreviver, mas desenvolver-se ou desenvolver-se para sobreviver. Morin (2002) propõe a necessidade da relação dialógica entre ordem e desordem, certeza e incerteza, organização e desorganização, para que ocorra um processo evolutivo, ou seja, para que qualquer coisa evolua, é necessário que ela saia do centro de equilíbrio, da sua ordem normal, do seu centro de referência, e passe por um processo de desequilíbrio, desordem e desorganização. O que se espera de uma organização é que o clímax seja rompido para que o desenvolvimento prossiga, ou seja, este clímax é o estado estacionário de uma organização mas que precisa da desordem para se desenvolver.

\section{Comunicação organizacional (re)significada}

Morin (1991) entende as organizações como um sistema vivo que se constitui de partes interdependentes entre si, que interagem e se transformam mutuamente no todo. Sob esta perspectiva a noção de organização necessita ser percebida como 
viva, capaz de transformar e de ser transformada através das relações que estabelece com a sociedade. Lapassade (1989) define organizações com pelo menos dois significados. Por um lado, designa um ato organizador que é exercido pelos sujeitos, como por exemplo, a organização de processos administrativos ou o ato e efeito de organizar, que pode ser uma das funções da administração. Por outro lado, o autor define organização como referente às realidades sociais ou à organização de uma coletividade instituída com vistas a objetivos definidos, à combinação de esforços para atingir propósitos coletivos, como uma entidade social em busca de interesses coletivos, ou ainda como um agrupamento planejado de pessoas que desempenham funções e trabalham conjuntamente para atingir objetivos comuns. É com base no entendimento de Morin (1991) e na segunda concepção de organização sugerida por Lapassade (1989) que este trabalho se apoia para os apontamentos .

Considerando que as organizações são vivas, abertas e alteram-se constantemente pelo processo interação, entende-se que esta interação é potencializada pelos processos de comunicação através da relação estabelecida entre dois ou mais sujeitos, na qual um sujeito compartilha alguma coisa, dando-lhe significado, e o outro gera, ou não, seu significante, buscando sempre a relação social. Porém, faz-se necessário diferenciar comunicação da informação, na qual a informação é a transmissão de alguma coisa e a comunicação a geração de significado pelo receptor do que foi informado (Wolton, 2010). Quanto maior o processo de interação com as informações transmitidas, maior a comunicação estabelecida e maiores são as potencialidades de alteração de uma organização que se considera aberta e viva.

Nesta interação estabelecida, se percebe a comunicação como a geração ou de um conflito, ou de um consenso. Quanto maior o consenso no processo de comunicação, menor são as possibilidade de uma organização sofrer alteração e romper seu clímax para a sua reconstrução e desenvolvimento, se constituindo assim como uma organização fechada. Quanto maior o conflito no processo comunicativo, maior é a interação entre os sujeitos e maiores são as possibilidades da organização sofrer alterações saindo do estado estacionário e passando a ser entendida como um organismo aberto.

Os processos de conflitos ou de consensos, se dá através da comunicação e ocorre por que toda a organização se mantém com base nos seres humanos que a compõem. Estes são capazes de interpretar seu contexto, que está representado pelos símbolos culturais, e de interagir, através de ações, com os estímulos de que são destinatários, muitas vezes rompendo o clímax que esta estabelecido. Assim, o processo de comunicação organizacional torna-se um processo cultural com a utilização de símbolos comuns, fomentado pela a interação social. Quanto mais ações conflituosas aos estímulos, mais a comunicação organizacional se retroalimenta e se autoproduz recursivamente. Isto acontece, em geral, por que dentro de uma mesma organização há uma pluralidade de sujeitos. Cada um destes sujeitos é ao mesmo 
tempo singular e universal. De acordo com Freitas (2000: 87), "somos ao mesmo tempo um individual e um coletivo, um sozinho e uma multidão, um ninguém e um todo-mundo, que se apresenta e representa nas relações múltiplas do cotidiano". Mesmo sendo individual e/ou coletivo, mesmo agindo na instância grupal e/ ou individual, nas relações sociais e/ou nas organizações, os sujeitos tornaram-se atores do contexto organizacional contemporâneo.

Em organizações abertas, nas quais os sujeitos tem a possibilidade de interagir mais nas suas relações sociais, o processo comunicativo se torna muito mais conflitante, pois cada um tem seus interesses sociais que são colocados em questão. Morin (2008b: 41) fala que a "ruptura do imprinting pode ser profunda e o desvio que jorra pela brecha pode evoluir em uma contestação radical capaz de resultar na queda de verdades reinantes", ou seja, a comunicação organizacional pode se tornar muita significativa, capaz de estabelecer verdades como absoluta, mas isto se dá temporariamente, pois as fortes interações nas relações sociais são capazes de derrubar os determinismo estabelecido nas organizações.

Com isto a comunicação organizacional é (re)inventada e (re)construída constantemente. Não se pode pensar em uma comunicação organizacional regida pelas lógicas de mercado, sendo simplificadas apenas na aplicação de instrumentos, buscando resultados e objetivos imediatos. Quando isto acontece, tem-se uma visão reducionista da comunicação, e atribui-se a esta comunicação a responsabilidade de constituição de todo o poder simbólico organizacional criado, levando em consideração que o sujeito é pouco ativo. Este sujeito, que (re)constrói a organização por um processo de comunicação conflitante, é capaz de recriar o significado das mesmas, com base no seu significante, no momento em que relaciona as informações recebidas através de estratégias de comunicação, com o seu simbolismo, imaginário e principalmente com a sua cultura. Porém, quando o processo de comunicação é consensual, tem-se os objetivos de estratégias rapidamente atingidos e a comunicação, pela interação, se finda não criando possibilidades de reconstrução da comunicação organizacional, sem abrir brechas ou romper com os imprinting.

Assim, é necessária a compreensão de que a comunicação organizacional é um processo que acontece em um sistema aberto, vivo e, quanto mais conflitante, maior a possiblidade de (re)construir a comunicação e consequentemente a organização. Segundo Srour (1998), as organizações como sistemas abertos se estabelecem como campos de forças que competem entre si para absorver energia do ambiente externo, processar insumos e gerar produtos. Para isto é necessário administrar pressões e fomentar grupos de apoio para criar credibilidade junto à sociedade. Neste sentido torna-se importante a capacidade de adaptação das organizações.

Porém, quando uma organização que não é aberta se concentra em seu planejamento estratégico de comunicação para efetivar a comunicação organizacional e buscar seus objetivos, esta em busca de um consenso, de uma estabilidade e pode 
ser considerada como uma organização fechada, nas quais os conflitos organizacionais não possuem espaço nas interação comunicacionais e os sujeitos deixam de ser multifacetados, para se tornarem pouco ativos.

\section{Constatações de um planejamento estratégico (re)siginificado pela Complexidade}

Giddens (2004) aponta que o comportamento humano é complicado e multifacetado e é muito pouco provável que uma única perspectiva teórica possa cobrir todas as suas características. A diversidade do pensamento teórico fornece uma fonte rica em ideias que podem ser a base de novas investigações e estimula as capacidades imaginativas tão essenciais ao progresso de qualquer trabalho, ainda mais, quando se trata de questões sociológicas, antropológicas e de comportamento humano.

As teorias sobre planejamento estratégico o consideram como sendo a utilização eficaz dos meios disponíveis na organização para exploração de condições favoráveis existentes no meio-ambiente externo e interno e que se efetiva através da gestão estratégica. A abordagem estratégica inclui o envolvimento organizacional, através do comprometimento em agir estrategicamente, e o planejamento é a metodologia gerencial que efetiva as estratégias como um conjunto de providências a serem tomadas para determinar a situação que se pretende no futuro com base nos acontecimentos do passado (Oliveira, 1999).

Kunsch (2003) aponta que o planejamento está no topo da pirâmide organizacional, envolve toda a organização e é de longo prazo. Em alguns momentos busca dar respostas mais imediatas as demandas ou ainda instrumentaliza as estratégias através de ações. Sob esta perspectiva o planejamento esta diretamente ligado a estratégias. Bueno (2005) entende a estratégia como a forma de definir e aplicar recursos com o fim de atingir objetivos previamente estabelecidos pela organização. Segundo o autor a palavra estratégia vem do latim strategia que, por sua vez, deriva de dois termos gregos: stratos ("exército") e agein ("conduzir", "guiar"). Portanto, o significado primário de estratégia é a arte de conduzir as operações militares, desenvolvendo habilidades para gerenciar um caminho a ser seguido, afim de se atingir um objetivo.

Porém, com o passar do tempo a palavra estratégia teve diferentes significados com variadas abordagens teóricas. A teoria clássica assume a estratégia pela perspectiva racional, voltada a maximização de lucro. Já a teoria evolucionista aposta na imprevisibilidade do mercado e na sobrevivência das empresas mais fortes com base no pensamento darwiniano e sempre que necessário reduz custos. A teoria processualista, assim como a evolucionista, não aceita a racionalidade do planejamento a longo prazo, mas não se julga refém do mercado e os seus resultados são obtidos de forma lenta e gradual por meio de experimentação e aprendizado pelas competências internas da organização. E por fim na teoria sistêmica a estratégia é 
vista como depende do mercado, mas também de condições sociais e culturais das organizações (Bueno, 2009).

Em todas as abordagens teorias sobre estratégias, a busca em atingir objetivos se torna evidente, assim como o fato de estar atrelado as lógicas do mercado. Então, quando se fala de um planejamento estratégico, se pensa que a estratégia estabelecida é o caminho para atingir um objetivo do planejamento com fins, quase sempre, mercadológicos. Deixa-se pouca brecha para o imprinting, pouco espaço para a renovação e reconstrução da organização e seus significados. Quando se fala em comunicação, obter um objetivo imediato, planejado e previamente estabelecido, rompe o processo de comunicação que se estabelece pela interação, pois chega-se a um consenso e não gera a possibilidade de conflito que vai fomentar a comunicação e fazer a organização crescer, se alterar e se reconstruir pelas relações sociais.

Quando se pensa em um planejamento estratégico para o desenvolvimento de comunicação organizacional, muitas vezes, pensa-se no estabelecimento do consenso para a obtenção do objetivo da organização. Se o objetivo é alcançado por meio de uma informação, volta-se a lógica de uma comunicação instrumentalista, na qual a estratégia é limitadora, e o estrategista prevê e articula os recursos comunicacionais necessários para garantir, simplesmente, a circulação de informações selecionadas e fazer com que os públicos reconheçam a organização, instituindo-a identitariamente, como referência. Isto somente funciona quando há um consenso ou uma aceitação da estratégia aplicada.

Esta concepção pode se tornar interessante para as organizações que tem como sistema produtivo um pensamento mecanicista, na qual a relação entre os sujeitos nem sempre é considerada como ponto produtivo. Por mais que as teorias organizacionais tenham evoluído para o entendimento das relações sociais, pessoais e sociológicas as teorias de planejamento e estratégias precisam ser mais flexíveis para dar mais espaço aos processos de comunicação.

Atualmente tem-se, principalmente nas organizações abertas, o desenvolvimento de uma abordagem sociológica da sua forma de produção, considerando as relações sócio-afetivas de seus públicos como fator decisivo na produção organizacional. Isto faz com as lógicas de um planejamento estratégico necessitem ser revistas, sob o enfoque sociológico, para que as relações dos sujeitos complexos possam buscar os resultados que a organização espera criando constantemente uma nova ordem.

É necessário que haja nas organizações espaço para que cada sujeito troque suas experiências com os outros na medida da identificação e significação de cada um com a organização e com seus pares. Se uma organização valoriza a relação sócio-afetiva de seus públicos, precisa compreender que a comunicação é a interação que acontece com base no conflito, e não o estabelecimento de uma estratégia informativa na busca um objetivo com consenso de comunicação. Assim, quanto maior o consenso da informação transmitida, melhor é o resultado da estratégia, 
porém a interação social diminui, consequentemente a comunicação também, e as formas produtivas podem ficar estagnadas.

De outro modo, quanto mais houver conflito, mais há possibilidade da comunicação de fato existir e novas brechas serem criadas para auto-eco-organização da organização. Quanto mais conflitante o processo comunicativo, maior a possibilidade para a comunicação acontecer em um grupo, uma vez em que o conflito sempre acontece de uma esfera individual para social. Com isto a comunicação conflitante abre brechas e pode auxiliar na trocas de experiência para o aprimoramento do processo produtivo.

Assim, percebe-se que as teorias sobre planejamento estratégico sempre evoluíram. Entretanto, esta reflexão considera, ainda que teoricamente, a possibilidade de se pensar o planejamento estratégico tenha como condição primeira de sua existência as relações sociais que se processam nas organizações. Com isto haverá a possibilidade da organização se reconstruir constantemente com a sustentação dos sujeitos que a compõem que são sujeitos complexos.

Com isto, pode-se pensar no desenvolvimento da comunicação organizacional, na qual as ações e atividades não tenham somente um fim mercadológico em vias de efetivação do planejamento estratégico, em um primeiro momento, mas que se pense na comunicação com seu sentido de interação e relação social sendo esta capaz de efetivar a produtividade da organização. Deste modo, as novas abordagens do planejamento estratégico na comunicação organizacional devem levar em consideração, também, as múltiplas áreas de atuação que os profissionais de comunicação possuem hoje e exercitarem as infinitas possibilidades de reconstrução das teorias, transcendendo os fins puramente mercadológicos, mas evidenciando as relações sócio-afetivas para a efetivação de uma comunicação organizacional capaz de reconstruir uma organização, assim como suas formas produtivas.

Caroline Delevati Colpo Professora da Universidade Feevale Doutora em Comunicação (PUCRS)

Recebido em março de 2015.

Aprovado em março de 2017. 


\section{Notas}

1. A comunicação organizacional (re)significada teve suas primeiras abordagens na tese de doutorado da autora. A comunicação organizacional e as relações de trabalho em cooperativas de economia solidária: a cultura simbólica tecendo a identidade e o imaginário dos cooperativados, 2012. Disponível em http://verum.pucrs.br/ppgcom 2. Espaço onde tudo acontece (Morin, 1991).

3. Por imprinting entende-se o proposto por Morin (2008b: 29) como determinismo organizador dos paradigmas e modelos explicativos. Associa-se ao determinismo organizado dos sistemas de convicção e de crença que, quando reinam em uma sociedade, impõem a todos a força imperativa do sagrado, a força normalizadora do dogma, a força proibitiva dos tabus. As doutrinas e ideologias dominantes dispõem também de força imperativa/coercitiva que leva a evidência aos convictos e o temor inibitório aos outros. O poder imperativo/proibitivo (...), crenças oficiais, doutrinas reinantes, verdades estabelecidas, determina os estereótipos cognitivos, preconceitos, crenças estúpidas não contestadas, absurdos triunfantes, rejeições de evidências em nome da evidência, faz reinar, sob todos os céus, os conformismos cognitivos e intelectuais.

\section{Referências}

BUENO, W. A comunicação empresarial estratégica: definindo os contornos de um conceito. Conexão - Comunicação e Cultura, v. 4, n. 7, 2005, p. 11-20.

. A comunicação como inteligência empresarial competitiva. In: KUNSCH, Margarida. Comunicação organizacional. São Paulo: Saraiva, 2009.

FREITAS, M. Cultura organizacional, Rio de Janeiro: Editora FGV, 2000.

GIDDENS, A. Sociologia. São Paulo: Record, 2004.

LAPASSADE, G. Grupos, organizações e instituições, Rio de Janeiro: Francisco Alves, 1989.

KUNSCH, M. Planejamento de Relações Públicas na Comunicação Integrada, São Paulo: Summus, 2003.

MORIN, E. Introdução ao pensamento complexo, Lisboa: Instituto Piaget, 1991.

. O método II: a vida da vida, Porto Alegre: Editora Sulina, 2002.

. O método III: o conhecimento do conhecimento. Porto Alegre: Editora Sulina, 2008a.

O método IV: as ideias. Porto Alegre: Editora Sulina, 2008b.

. O método V: a humanidade da humanidade. Porto Alegre: Editora Sulina, 2007.

OLIVEIRA, D. Planejamento estratégico: conceitos, metodologia e práticas, São Paulo: Atlas, 1999. SROUR, R. Poder, cultura e ética nas organizações. São Paulo: Campus, 1998.

WOLTON, D. Informar não é comunicar. Porto Alegre: Editora Sulina, 2010. 


\section{Resumo}

Este estudo, através de uma análise teórica e dos resultados de estudos da tese de doutorado da pesquisadora, discute o planejamento estratégico na comunicação de organizações sob a perspectiva do Paradigma da Complexidade. Investe-se na possibilidade de compreender a (re)significação da comunicação organizacional com maior enfoque na comunicação humana sujeito/sujeito e organização/sujeito transcendendo a abordagem instrumental. Com isto acredita-se na necessidade de (re)significação do entendimento de planejamento estratégico. Para tal, entende-se o Paradigma da Complexidade, que desfaz os limites entre diferentes áreas do saber com a sua característica transdisciplinar, sendo capaz de autoproduzir e auto organizar a comunicação das organizações quando se tem enfoque no sujeito. Este texto introduz o questionamento sobre a aplicabilidade, ou não, do planejamento estratégico na comunicação organizacional (re)significada.

\section{Palavras-chave}

Comunicação organizacional. Planejamento de comunicação. Paradigma da Complexidade.

\section{Abstract}

This study, through a theoretical analysis and the results of studies based on the researcher's doctorate thesis, discusses the strategic planning of communication in organizations from the perspective of the Complexity Paradigm. It invests in the possibility of understanding a new meaning of the organizational communication with emphasis in the human communication individual/individual and organization/individual transcending the instrumental approach. By this idea is believed in the necessity of a new meaning of understanding from strategic planning. To this purpose it is understandable the Complexity Paradigm, which undoes the limits among different settings of knowledge with its transdisciplinary feature, been able to self-organize and self-produce the communication in organizations when there is a focus in the individual. This text introduces the questioning of the applicability or not of strategic planning in organizational communication in a new meaning.

\section{Keywords}

Organizational communication. Strategic planning. Complexity Paradigm. 